\title{
AVALIAÇÃO DA BALNEABILIDADE E QUALIDADE DA ÁGUA DA REPRESA LARANJA-DOCE NO MUNICÍPIO DE MARTINÓPOLIS-SP
}

Ana Paula Jambers Scandelai ${ }^{1}$, Marina Ramos Furlan Solina ${ }^{1}$, Alexandre Teixeira de Souza ${ }^{2}$

${ }^{1}$ Discente e bolsista do PROBIC, ${ }^{2}$ Docente do curso de Engenharia Ambiental da UNOESTE, Presidente Prudente, SP. e-mail: paulascandelai@hotmail.com

\section{RESUMO}

A Represa Laranja-Doce, localizada em Martinópolis/SP, vem sendo intensamente degradada por ações antrópicas. Suas margens apresentam elevado potencial turístico, sendo extremamente importante a avaliação da sua qualidade da água. Neste projeto, foram realizadas análises da balneabilidade e qualidade da água em diferentes pontos de amostragem ao longo da represa, seguindo as recomendações da norma NBR-9897. O parâmetro indicador para a classificação quanto à sua balneabilidade foi a concentração de coliformes totais (CONAMA 357/05). Para a determinação da qualidade da água foi utilizado o Índice de Qualidade da Água, calculado através das análises dos parâmetros: oxigênio dissolvido, coliformes termotolerantes, $\mathrm{pH}, \mathrm{DBO}_{5}{ }^{20}$, sólidos totais dissolvidos, fósforo total, nitrogênio total, temperatura e turbidez. Dessa forma, este trabalho contribuirá para a formação de um banco de dados importante e inédito sobre as características físicas, químicas e biológicas da Represa, que poderão servir de base para o planejamento da Orla Turística do Município de Martinópolis/SP.

Palavras-chave: Balneabilidade, Índice da Qualidade da Água, Represa Laranja-Doce, Preservação e Conservação, Meio Ambiente.

\section{EVALUATION OF WATER QUALITY AND BALNEABILITY DAM LARANJA-DOCE COUNTY IN MARTINÓPOLIS-SP}

\begin{abstract}
The Laranja-Doce Dam, located in Martinópolis/SP, has been heavily degraded by human actions. Its margins have high tourism potential, it is extremely important to evaluate its water quality. In this project, were analyzed and the bathing water quality at different sampling points along the dam, following the recommendations of the NBR-9897. The indicator parameter for classification as to their bathing was the concentration of total coliform (CONAMA 357/05). To determine the quality of water was used Water Quality Index, calculated by analyzing the parameters: dissolved oxygen, fecal coliform, $\mathrm{pH}, \mathrm{DBO}_{5}{ }^{20}$, total dissolved solids, total phosphorus, total nitrogen, temperature and turbidity. Thus, this work will contribute to the formation of a database on the important and novel physical, chemical and biological Dam, which could serve as a basis for planning Rim Tourist Municipality of Martinópolis/SP.
\end{abstract}

Keywords: bathing, Water Quality Index, Dam Laranja-Doce, Preservation and Conservation, Environment. 


\section{INTRODUÇÃO}

Além de depreciar a fauna e flora aquática, a poluição dos recursos hídricos causada por ações antrópicas, pode acarretar inúmeros problemas à saúde humana, pois a água é empregada como veículo pelos agentes patogênicos na disseminação de doenças (GRABOW, 1996 apud GREGHI, 2005).

A qualidade da água é um termo que não se restringe à determinação da pureza da mesma, mas às suas características desejadas para os seus diversos usos. Tanto as características físico-químicas quanto as biológicas da água podem ser alteradas. $\mathrm{Na}$ maioria dos casos, essa alteração é causada pela poluição, que pode ter diversas origens $(\mathrm{BILICH}$; LACERDA, 2005).

Para caracterizar esta qualidade, foram realizadas análises da balneabilidade e qualidade da água em diferentes pontos de amostragem ao longo da represa. O parâmetro indicador para a classificação quanto à sua balneabilidade em termos sanitários foi o número de coliformes totais, enquanto que para a determinação da qualidade da água foi utilizado o Índice de Qualidade da Água (IQA-CETESB), calculado através das análises dos parâmetros: oxigênio dissolvido, coliformes termotolerantes (fecais), $\mathrm{pH}, \mathrm{DBO}_{5}{ }^{20}$, sólidos totais dissolvidos, fósforo total, nitrogênio total, temperatura e turbidez.

Segundo a CETESB (2004), balneabilidade é a qualidade das águas destinadas à recreação de contato primário (direto e prolongado) com a água, onde a possibilidade de ingerir quantidades apreciáveis de água é elevada. As águas recreacionais contêm geralmente uma mistura de microrganismos patogênicos e não patogênicos, que podem ser derivados dos efluentes do esgoto, do uso pela população e animais. Além disso, podem também conter microrganismos patogênicos de vida livre, que causam infecções gastrointestinais após ingestão, ou infecções respiratórias (WHO, 2003).

Segundo a Resolução CONAMA 274/00, que trata especificamente da balneabilidade, a qualidade das águas doces, salobras e salinas destinadas à balneabilidade terá sua condição avaliada nas categorias própria e imprópria. As águas consideradas próprias poderão ser subdivididas em: Excelente, Muito Boa e Satisfatória. As águas são consideradas impróprias quando ultrapassarem os índices bacteriológicos admitidos, presença de resíduos como esgotos sanitários e outras substâncias capazes de oferecer riscos à saúde, floração de algas ou outros organismos ou presença de transmissores potenciais de doenças de veiculação hídrica.

A área de estudo, Represa Laranja-Doce, localiza-se no Município de Martinópolis/SP, situa-se a $12 \mathrm{Km}$ da cidade e, de acordo com o Comitê de Bacias Hidrográficas dos Rios Aguapeí e Peixe (CBH-AP), pertence à Bacia Hidrográfica do Rio do Peixe (UGRHI 21), possui uma área de $9.156 \mathrm{Km}^{2}$, vazão média de $84 \mathrm{~m}^{3} / \mathrm{s}$ e vazão mínima de $32 \mathrm{~m} 3 / \mathrm{s}$. Possui um espelho d'água propício à natação, mergulho, prática da pesca e esportes náuticos. Devido a este potencial turístico, observa-se a necessidade de assegurar um acompanhamento da qualidade da água e da balneabilidade do reservatório.

O presente trabalho tem como objetivo de estudo, avaliar o Índice de Balneabilidade e o Índice de Qualidade da Água (IQA) da Represa Laranja-Doce do Município de Martinópolis/SP, a fim de verificar as condições da água da represa baseada nas Resoluções CONAMA n. 274/00 e n०. 357/05; e a partir das informações obtidas, diagnosticar a real situação ambiental e revelar possíveis riscos à saúde dos seus usuários, bem como propor medidas de orientação às ações de gestão pública do município. 


\section{METODOLOGIA}

Inicialmente realizaram-se revisões bibliográficas e levantamentos de dados disponíveis necessários ao trabalho.

Os pontos de coleta da água para análise foram delimitados segundo a NBR-9897, que dispõe sobre "Planejamento de amostragens de efluentes líquidos e corpos receptores" e estão ilustrados na Figura 1.

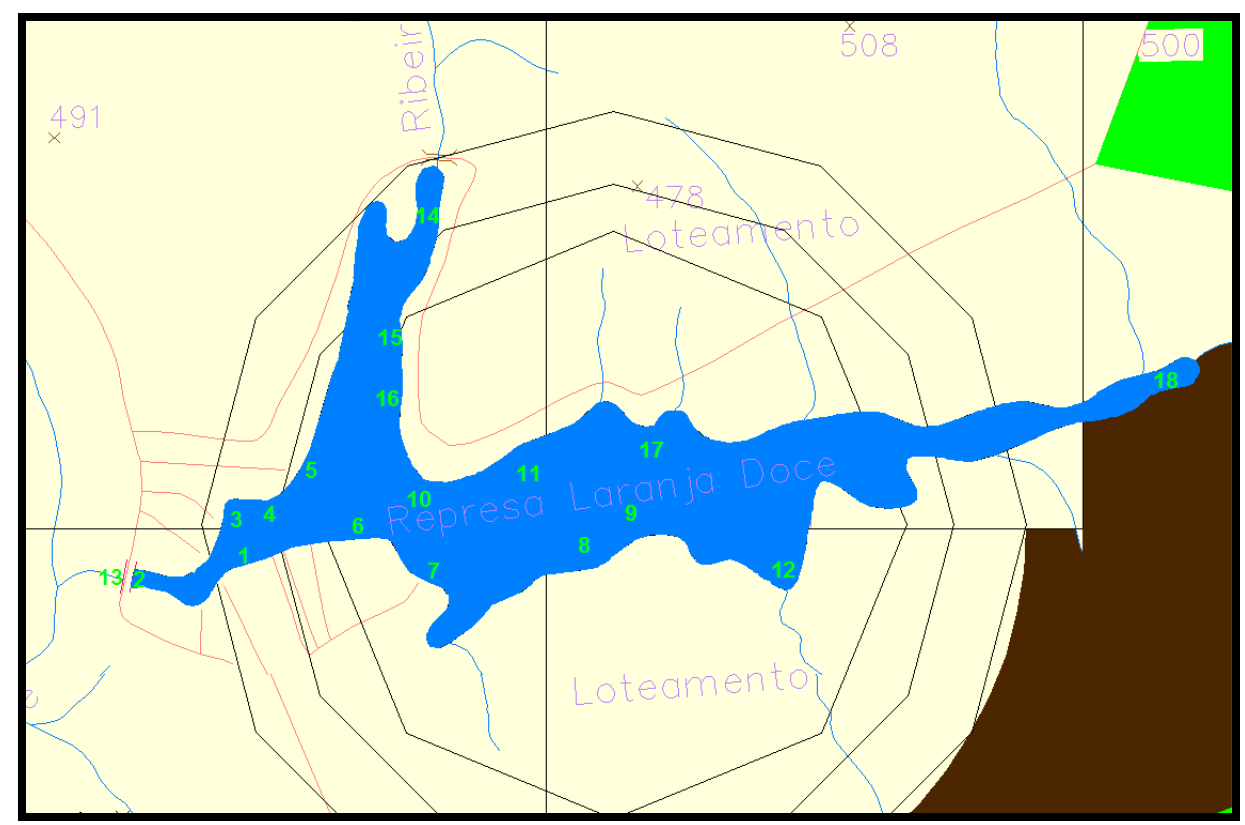

Figura 1. Represa Laranja-Doce com seus respectivos pontos de coleta para análise da água. Fonte: Prefeitura de Martinópolis (2009), escala 1:95.000.

As amostras foram coletadas segundo indicação da NBR-9897, de modo sub-superficial, a aproximadamente $20 \mathrm{~cm}$ de profundidade, coletando-se um litro de água em cada ponto, para encaminhamento ao Laboratório de Análises de Águas da Universidade do Oeste Paulista (UNOESTE), onde se realizaram as análises dos seguintes parâmetros: Coliformes totais e Escherichia coli (para o Índice de Balneabilidade), coliformes termotolerantes, $\mathrm{pH}, \mathrm{DBO}_{5}{ }^{20}$, nitrogênio total, fósforo, temperatura, turbidez, sólidos totais e oxigênio dissolvido (para o Índice de Qualidade da Água). A temperatura das amostras foi medida in situ, através de um termômetro. Ao mesmo tempo em que se realizam as coletas das amostras, houve a verificação dos problemas ambientais e o levantamento fotográfico no entorno da represa.

A classificação das águas em próprias (excelente, muito boa ou satisfatória) ou impróprias à balneabilidade segue o parâmetro do número de coliformes totais, indicado nas Resoluções CONAMA n. 274/00 e n. 357/05. A água amostrada em cada ponto de coleta é enquadrada nas categorias Excelente, Muito Boa, Satisfatória e Imprópria, conforme indicado no Quadro 1. 
Quadro 1. Classificação das águas para balneabilidade, segundo limite de coliformes totais (Resolução CONAMA 274/00). NMP: número mais provável. Fonte: RES. CONAMA 274/00 e CONAMA $357 / 05$.

\begin{tabular}{|c|c|c|c|c|c|}
\hline Categoria & $\begin{array}{l}\text { Porcentage } \\
\text { m do tempo }\end{array}$ & $\begin{array}{l}\text { Limite de } \\
\text { Coliforme Fecal } \\
\text { (NPM/100ml) }\end{array}$ & $\begin{array}{l}\text { Limite de } \\
\text { Escherichia coli } \\
\text { (UFC/100ml) }\end{array}$ & $\begin{array}{l}\text { Limite de } \\
\text { Enterococos } \\
\text { (UFC/100ml) }\end{array}$ & $\begin{array}{c}\text { Limite de } \\
\text { Coliformes } \\
\text { Totais } \\
\text { (UFC } / 100 \mathrm{ml} \text { ) }\end{array}$ \\
\hline \multicolumn{6}{|c|}{ PRÓPRIA } \\
\hline Excelente & \multirow{3}{*}{$\begin{array}{l}\text { Valor máximo } \\
\text { em } 80 \% \text { ou } \\
\text { mais do } \\
\text { tempo }\end{array}$} & 250 & 200 & 25 & \\
\hline Muito Boa & & 500 & 400 & 50 & \\
\hline $\begin{array}{l}\text { Satisfatóri } \\
\text { a }\end{array}$ & & 1000 & 800 & 100 & \\
\hline \multicolumn{6}{|c|}{ IMPRÓRIA } \\
\hline \multicolumn{2}{|c|}{$\begin{array}{c}\text { Superior ao valor indicado } \\
\text { em } 20 \% \text { do tempo }\end{array}$} & 1000 & 800 & 100 & \\
\hline \multicolumn{2}{|c|}{$\begin{array}{l}\text { Superior ao valor indicado } \\
\text { na última amostragem }\end{array}$} & 2500 & 2000 & 400 & 5000 \\
\hline
\end{tabular}

Para a identificação da qualidade da água em cada ponto da represa foi utilizado o Índice de Qualidade da Água (IQA), calculado pelo produtório ponderado da qualidade de água correspondente aos parâmetros: temperatura da amostra, $\mathrm{pH}$, oxigênio dissolvido $\%$ de saturação), demanda bioquímica de oxigênio (cinco dias a $20^{\circ} \mathrm{C}$ ), coliforme fecal, nitrogênio total, fósforo total, resíduo total e turbidez (CETESB, 2001).

Este indicador de qualidade representa uma ferramenta prática, de informação eficiente, obtida por meio da indexação das informações de diversos parâmetros ou variáveis analisadas. Os resultados poderão diagnosticar a real situação ambiental que se encontra as águas da represa, propiciando tomadas de decisões com relação ao gerenciamento deste recurso hídrico.

\section{RESULTADOS}

O Quadro 02 demonstra os 18 pontos analisados com suas respectivas qualidades de água ao longo do período de estudo. De maneira geral, a Represa Laranja-Doce apresentou valores entre "Bom" e "Aceitável" nos pontos de amostragem, sendo que o Ponto 18 foi o que apresentou melhor qualidade com um valor de
59,24 , visto que é neste ponto que ocorre a entrada de água da represa. O Ponto 14 foi o que apresentou menor valor de qualidade da água, assim como apresentou os maiores níveis de DBO (22,5 mg. - $\left.^{-1}\right)$ e de turbidez (31,0 FAU).

\section{DISCUSSÃO}

Para classificação das águas em próprias (excelente, muito boa ou satisfatória) ou impróprias à balneabilidade foi utilizado o parâmetro: concentração de coliformes fecais, como indicado na Resolução CONAMA 274/00.

Foram analisados experimentalmente em laboratório a concentração de coliformes fecais nos 18 pontos de amostragem e comparados com o Quadro 01. Verificou-se que a balneabilidade em $100 \%$ das amostras manteve-se com classificação "Imprópria", com um pico de 120.000 UFC.100 $\mathrm{mL}^{-1}$ (Ponto 5) de coliformes totais, devido à maior concentração de pessoas no local, por se tratar de uma área com condomínios construídos. Os valores estiveram acima dos permitidos pela Resolução CONAMA $n^{\circ}$. 274/00 (até 5000 UFC. $100 \mathrm{~mL}^{-1}$ ).

Esta elevação nos coliformes totais pode estar relacionada com a atividade de pecuária extensiva inserida no entorno do reservatório, que 
com a chegada das chuvas e o aumento do volume do reservatório no início do período de estiagem, pode carrear material das margens para o corpo d'água.

Os pontos analisados no presente projeto (Quadro 2) apresentaram boas condições para a recreação, com a classificação variando entre
"Boa e Aceitável", contribuindo para o potencial turístico da região e para seu aproveitamento múltiplo, devendo apenas ser realizadas ações de melhorias ambientais ao longo da represa, a fim de melhorar a qualidade da água nos pontos com índice "aceitável".

Quadro 2. Valores de IQA calculados a partir dos dados coletados.

\begin{tabular}{|c|c|c|c|}
\hline $\begin{array}{l}\text { Ponto de } \\
\text { Amostragem }\end{array}$ & Valor do IQA & Nível de Qualidade & Cor \\
\hline 01 & 46,07 & Aceitável & \\
\hline 02 & 51,62 & Boa & \\
\hline 03 & 48,09 & Aceitável & \\
\hline 04 & 51,34 & Aceitável & \\
\hline 05 & 42,79 & Aceitável & \\
\hline 06 & 56,73 & Boa & \\
\hline 07 & 56,68 & Boa & \\
\hline 08 & 57,05 & Boa & \\
\hline 09 & 58,49 & Boa & \\
\hline 10 & 53,44 & Boa & \\
\hline 11 & 48,45 & Aceitável & \\
\hline 12 & 57,76 & Boa & \\
\hline 13 & 54,90 & Boa & \\
\hline 14 & 39,54 & Aceitável & \\
\hline 15 & 50,33 & Aceitável & \\
\hline 16 & 58,85 & Boa & \\
\hline 17 & 59,13 & Boa & \\
\hline 18 & 59,24 & Boa & \\
\hline
\end{tabular}

\section{CONCLUSÃO}

De forma geral, a Represa Laranja-Doce apresentou uma condição boa em $61 \%$ dos casos. Apesar desta boa qualidade o local, ainda não dispõe de dispositivos básicos para informar o usuário da qualidade e/ou riscos que pode enfrentar ao se utilizar as águas da represa.

Embora haja instrumentos e políticas para a manutenção da qualidade da água, o monitoramento e a fiscalização, são indispensáveis, e devem fazer parte do grupo de ações que tanto a prefeitura quanto o estado deveriam se ater.
Frente aos fatos e resultados apresentados, algumas ações para o acompanhamento da balneabilidade no reservatório são sugeridas:

- Elaboração de um plano para o monitoramento, com parceria do poder público;

- Fornecer um canal de informação com o usuário, através de placas de sinalização da qualidade da água;

- Realizar de maneira mais minuciosa uma pesquisa de acompanhamento dos tipos de usuários do balneário; 
- Pesquisar informações sobre a relação entre doenças gastrointestinais e frequentadores das praias;

- O desenvolvimento de técnicas para um melhor aprimoramento tanto dos métodos mais rápidos e eficazes, quanto a tomada de decisão dos riscos à população é uma ação que precisa ser estimulada;

\section{REFERÊNCIAS}

ABNT - ASSOCIAÇÃO BRASILEIRA DE NORMAS TÉCNICAS. NBR 9897: Planejamento de amostragem de efluentes líquidos e corpos receptores. Jun., 1987.

BILICH, M. R.; LACERDA, M. P. C. Avaliação da qualidade da água do Distrito Federal (DF), por meio de geoprocessamento. Anais. XII Simpósio Brasileiro de Sensoriamento Remoto, Goiânia, Brasil, 16-21 abril 2005, INPE, p. 2059-2065.

CBH-AP - COMITÊ DE BACIAS HIDROGRÁFICAS DOS RIOS AGUAPEÍ E PEIXE. Unidade de Gerenciamento de Recursos Hídricos-21. Disponível em: $<$ http://www.comiteap.sp.gov.br/site_estr_inst_21. html>. Acesso em 12/08/2011.

CETESB - COMPANHIA DE TECNOLOGIA E SANEAMENTO AMBIENTAL. Balneabilidade de Praias e Reservatórios. São Paulo: Cetesb, 2004. Disponível em: <www.cetesb.sp.gov.br>. Acesso em 16/08/2011.

CETESB - COMPANHIA DE TECNOLOGIA DE SANEAMENTO AMBIENTAL. Relatório de qualidade das águas interiores do estado de São Paulo, 2001. São Paulo: Cetesb, v.1, 214p., 2001.

CETESB - COMPANHIA DE TECNOLOGIA E SANEAMENTO AMBIENTAL. Relatório de qualidade das águas interiores do estado de São Paulo, 1995. São Paulo: Cetesb, 1995.

CETESB - COMPANHIA DE TECNOLOGIA E SANEAMENTO AMBIENTAL. Modelo Matemático para Cálculo do Índice de Qualidade de Água (IQA), Relatório R.178. São Paulo, 1977.

CONAMA - CONSELHO NACIONAL DO MEIO AMBIENTE. Resolução 274/2000.

CONAMA - CONSELHO NACIONAL DO MEIO AMBIENTE. Resolução 357/2005.
ESTEVES, F. A. Fundamentos de Limnologia. 2. ed. Rio de Janeiro. 1998.

GREGHI, S. Q. Avaliação da eficiência de métodos rápidos usados para detecção de Coliformes Totais e Coliformes Fecais em amostras de água em comparação com técnicas de fermentação em tubos múltiplos. Universidade Estadual Paulista, Araraquara, 2005.

SIRIGATE, P.; STADLER, C. C.; OROSKI, F. I.; KOVALESKI, J. L. Gestão da qualidade ambiental da água de mananciais de abastecimento público como estratégia de redução de custos. $\mathbf{X X X}$ Encontro Nacional de Engenharia de Produção - Porto Alegre - RS, 2005.

SPERLING, M. V. Estudo e modelagem da qualidade da água de rios, $1^{\mathrm{a}} \mathrm{Ed}$. - Belo Horizonte: Departamento de Engenharia Sanitária e Ambiental; UFMG; 2007.

SPERLING, M. V. Introdução à qualidade da água e ao tratamento de esgoto, $2^{\underline{a}}$ ed. - Belo Horizonte: Departamento de Engenharia Sanitária e Ambiental; UFMG; 243p. 1996.

VASILIO, V. A. A. Balneabilidade, Índice de Qualidade da Água e Bioensaios de Toxicidade nas praias do Reservatório de Ilha Solteira/SP. Dissertação (mestrado) UNESP. Ilha Solteira. 2006. 145p.

WHO - WORLD HEALTH ORGANIZATION. Guidelines for a Safe Recreational Water environments, v. 1, Genebra, 2003. 